\title{
Common conditions associated with mandibular canal widening: A literature review
}

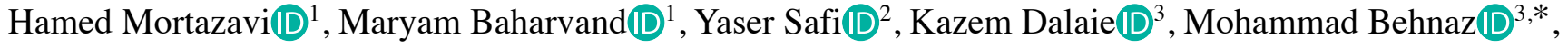 \\ Fatemeh Safari(D) \\ ${ }^{1}$ Department of Oral Medicine, School of Dentistry, Shahid Beheshti University of Medical Sciences, Tehran, Iran \\ ${ }^{2}$ Department of Oral and Maxillofacial Radiology, School of Dentistry, Shahid Beheshti University of Medical Sciences, Tehran, Iran \\ ${ }^{3}$ Department of Orthodontic, School of Dentistry, Shahid Beheshti University of Medical Sciences, Tehran, Iran \\ ${ }^{4}$ School of Dentistry, Shahid Beheshti University of Medical Sciences, Tehran, Iran
}

\section{ABSTRACT}

\begin{abstract}
Purpose: The aim of this study was to review the common conditions associated with mandibular canal widening. Materials and Methods: General search engines and specialized databases including Google Scholar, PubMed, PubMed Central, Science Direct, and Scopus were used to find relevant studies by using the following keywords: "mandibular canal," "alveolar canal," "inferior alveolar nerve canal," "inferior dental canal," "inferior mandibular canal," "widening," "enlargement," "distension," "expansion," and "dilation."

Results: In total, 130 articles were found, of which 80 were broadly relevant to the topic. We ultimately included 38 articles that were closely related to the topic of interest. When the data were compiled, the following 7 lesions were found to have a relationship with mandibular canal widening: non-Hodgkin lymphoma, osteosarcoma, schwannoma, neurofibroma, vascular malformation/hemangioma, multiple endocrine neoplasia syndromes, and perineural spreading or invasion.

Conclusion: When clinicians encounter a lesion associated with mandibular canal widening, they should immediately consider these entities in the differential diagnosis. Doing so will help dentists make more accurate diagnoses and develop better treatment plans based on patients' radiographs.(Imaging Sci Dent 2019; 49: 87-95)
\end{abstract}

KEY WORDS: Mandibular Nerve; Odontogenic Cysts; Odontogenic Tumors

\section{Introduction}

The mandibular canal, also known as the inferior alveolar nerve canal, is a bilateral anatomical structure in the mandible. It has an S-shaped pattern with a diameter of 2-2.4 mm. The mandibular canal is located most laterally and closest to the buccal cortical bone in the third molar region and approximates the lingual plate in the first molar region. The canal path approximates the buccal cortical plate between the premolar teeth before exiting the mandible through the mental foramen. The lowest position of the mandibular canal is in the region of the first molar to the

Received December 19, 2018; Revised March 18, 2019; Accepted April 7, 2019 *Correspondence to : Prof. Mohammad Behnaz

Department of Orthodontics, School of Dentistry, Shahid Beheshti University of Medical Sciences, 1983969411 Shahriari Square, Velenjak, Tehran, Iran

Tel) 98-912-3278021, E-mail) behnaz1357@yahoo.com second premolar, where the canal is approximately $7.5 \mathrm{~mm}$ from the inferior border of the mandible. At this location, the inferior alveolar nerve branches into the incisive and mental nerves. The distance between the mandibular canal and the buccal cortical plate in the molar region is greater than that in the ramus region, and may vary from $0.57 \mathrm{~mm}$ to $5.8 \mathrm{~mm}$ in the ramus region and from $0.40 \mathrm{~mm}$ to $70 \mathrm{~mm}$ in the molar region. ${ }^{1,2}$ The mandibular canal has several normal anatomical variations, such as a bifid canal, a trifid canal, or an enlarged canal. ${ }^{1,3}$ However, mandibular canal widening is a rare finding. When encountered, several benign and malignant conditions need to be excluded from the list of differential diagnoses before diagnosing it as a normal anatomical variant. ${ }^{3,4}$ Clinically, widening of the mandibular canal may be accompanied by sensory disturbances. Thus, radiographic assessment plays a fundamental role in the differential diagnosis. Panoramic radiography,

Copyright (c) 2019 by Korean Academy of Oral and Maxillofacial Radiology

This is an Open Access article distributed under the terms of the Creative Commons Attribution Non-Commercial License (http://creativecommons.org/licenses/by-nc/3.0) which permits unrestricted non-commercial use, distribution, and reproduction in any medium, provided the original work is properly cited. Imaging Science in Dentistry · pISSN 2233-7822 eISSN 2233-7830 
computed tomography, magnetic resonance imaging, and cone-beam computed tomography are suitable imaging modalities for thoroughly evaluating the characteristics of the mandibular canal, such as its position and diameter. ${ }^{1,5}$ A comprehensive literature review by the authors yielded 11 entities that might cause enlargement of the mandibular canal; these entities can be classified into the following 5 broad categories: (1) neoplastic (malignant and benign) lesions, (2) vascular/neurogenic malformations, (3) endocrine diseases, (4) inflammatory/reactive processes, and (5) perineural invasion. These conditions should be taken into consideration in the differential diagnosis of mandibular canal widening to ensure an accurate diagnosis and efficient treatment planning.

\section{Materials and Methods}

In this narrative review, the first author and the corresponding author carried out an electronic search of the literature in the Google Scholar, PubMed, PubMed Central, Science Direct, and Scopus databases for relevant articles using the following keywords: "mandibular canal," "alveolar canal," "inferior alveolar nerve canal," "inferior dental canal," "inferior mandibular canal," "widening," “enlargement," "distension," "expansion," and "dilation." A total of 130 articles were retrieved, of which 80 were relevant to our topic of interest. Forty-two articles were excluded since they were duplicates, were written in languages other than English, or their full texts were not available. Finally, 38 relevant English-language articles published from 1985 to 2017 were included in the study, comprising 21 original articles, 7 review articles, and 10 case reports and case series.

\section{Results}

After data collection, 7 entities were found to be correlated with mandibular canal widening: non-Hodgkin lymphoma, osteosarcoma, schwannoma, neurofibroma, vascular malformation/hemangioma, multiple endocrine neoplasia syndromes, and perineural spreading or invasion. Nearly all lesions associated with mandibular canal enlargement are of a neoplastic nature; therefore, a prompt diagnosis is quite important. The findings of this article will help clinicians detect such lesions more precisely. The characteristics of these lesions are summarized in Table 1.

\section{Non-Hodgkin lymphoma}

Non-Hodgkin lymphoma is classified as a lympho-proliferative disorder, and $20 \%-30 \%$ of cases occur at extran- odal sites. The gastrointestinal tract and skin are the most commonly involved sites. ${ }^{6,7}$ Bone involvement is rare, accounting for $5 \%$ of extranodal lymphomas. ${ }^{7}$ The sinonasal region is the most commonly affected area in the head and neck region. Involvement of the sinonasal region commonly occurs in individuals 40-45 years of age. Around 15\%$45 \%$ of non-Hodgkin lymphomas of the oral cavity involve both the maxilla and mandible, and only $0.6 \%$ affect the mandible alone. Furthermore, non-Hodgkin lymphoma has a male predilection. ${ }^{3,6,7}$ Oral non-Hodgkin lymphomas are often characterized by a bony swelling, which can be symptomatic or asymptomatic, as well as tooth mobility, pathological fractures, and sensory disturbances. ${ }^{3,7}$ This entity has no pathognomonic radiographic feature, but it usually manifests as a radiolucency with poorly-defined margins. ${ }^{7}$ Other radiographic findings include loss of cortical definition, widening of the periodontal ligament, nasal cavity and cavernous sinus enlargement, mental foramen widening, and dilation of the mandibular canal. ${ }^{3,7,8}$ Buric et al., ${ }^{9}$ and Bertilotto et al. ${ }^{10}$ reported that non-Hodgkin lymphomas of the mandible are rare, but can cause diffuse continuous widening of the mandibular canal (Fig. 1) associated with ice-cold numbness. Barber et al. ${ }^{11}$ reported fusiform widening of the mandibular canal or mental foramen in non-Hodgkin lymphoma patients. Non-Hodgkin lymphoma of the mandible may involve the canal via 2 mechanisms. It may arise from the bone, wrap around the mandibular canal, and infiltrate into it later, or it may arise from the lymphoid tissue of the mandibular canal, grow with neural and perineural spreading, and slowly expand or destroy the surrounding bone over time. ${ }^{?}$

\section{Osteosarcoma}

Osteosarcoma is the second most common primary malignant bone tumor, after multiple myeloma. Osteosarcoma of the jaws accounts for $5 \%$ to $13 \%$ of all osteosarcomas. Over $80 \%$ of the cases are seen in patients between 5 to 25 years of age, but it has a second, lower peak of incidence in the fifth and sixth decades of life. ${ }^{7}$ The mandible is more commonly affected than the maxilla. No sex or race predilection has been reported for this entity. ${ }^{12}$ It often manifests as a firm swelling that enlarges over time. Paresthesia, pain, tooth mobility, and facial bone distortion have also been reported. ${ }^{3,7}$ Osteosarcoma is often suspected after noticing radiographic changes. The time interval between the development of initial symptoms and final diagnosis may vary from 3 to 5 months. ${ }^{7}$ The triad of mandibular canal widening, a widened periodontal ligament, and a sun-ray appearance on conventional or panoramic radiographs are almost 


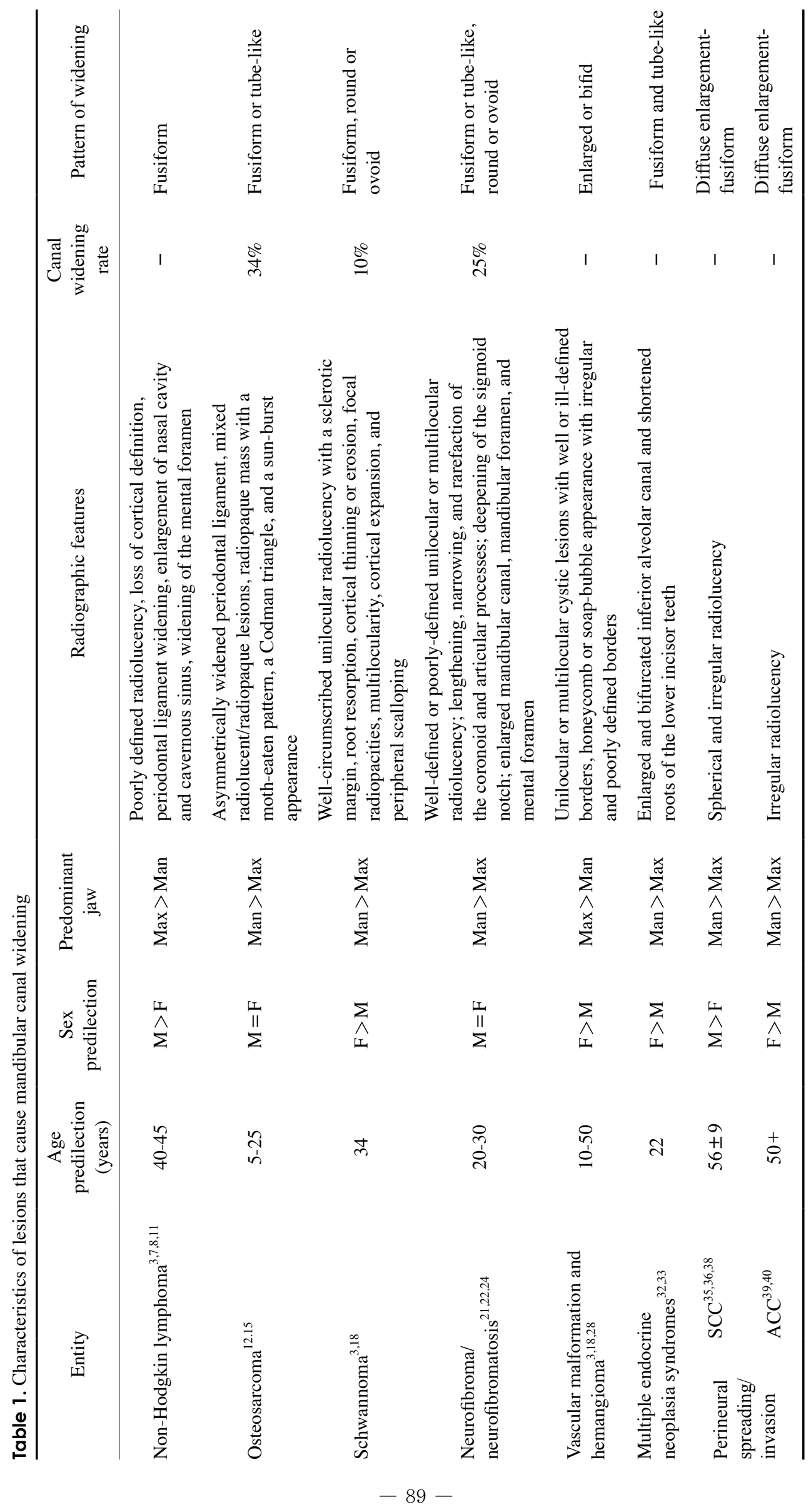



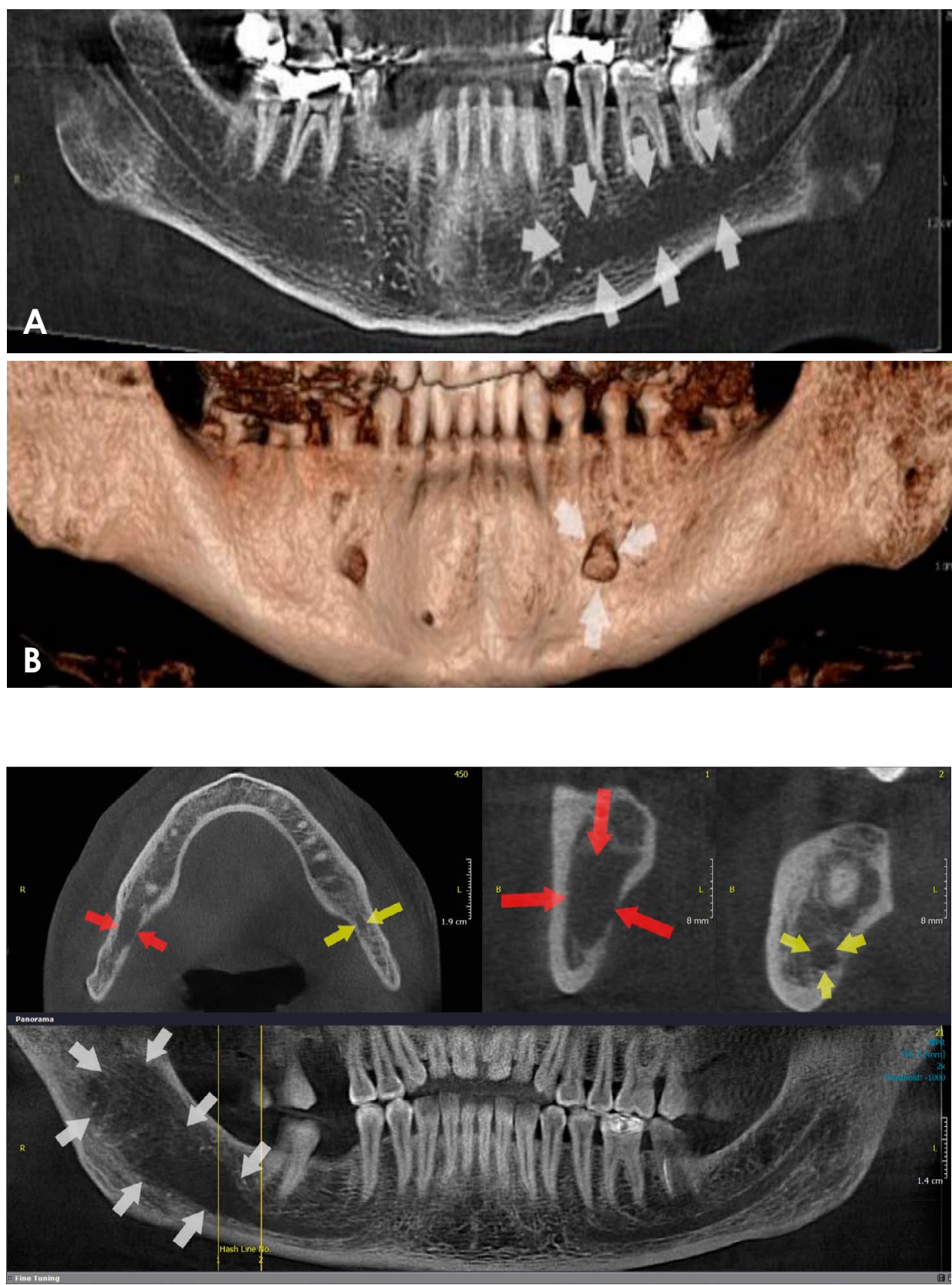

Fig. 1. Panoramic reconstructed and 3-dimensional cone-beam computed tomographic images show mandibular canal and mental foramen widening in a patient with non-Hodgkin lymphoma, respectively.
Fig. 2. Cone-beam computed tomographic images show mandibular canal widening in a patient with osteosarcoma (arrows show the normal canal and mandibular canal widening). pathognomonic for mandibular osteosarcoma. ${ }^{3}$ According to Yagan et al., ${ }^{13}$ enlargement of the mandibular canal (Fig. 2 ) is an early sign of mandibular osteosarcoma. Moreover, $34 \%$ of the involved mandibles exhibit structural changes of the alveolar canal. ${ }^{14}$ Involvement of the alveolar nerve in osteosarcoma causes fusiform or tube-like widening of the mandibular canal. ${ }^{3}$ Garrington et al. ${ }^{15}$ reported an asymmetrically widened periodontal ligament of 1 or more teeth on a periapical dental radiograph early after the onset of osteosarcoma of the jaws, before the appearance of any other distinctive radiographic features. Mixed radiolucent/ radiopaque lesions, a radiopaque mass with a moth-eaten pattern, a Codman triangle, and a sun-burst appearance are among other radiographic findings of osteosarcoma. ${ }^{12}$

\section{Schwannoma}

Schwannoma, also known as neurinoma, neurilemmoma, perineural fibroblastoma, and benign peripheral nerve sheath tumor, is a benign neoplasm of differentiated schwannoma cells. ${ }^{3}$ The head and neck are affected in $24 \%$ $48 \%$ of cases, and schwannoma shows a predilection for soft tissue. Intraosseous schwannoma is a rare occurrence because central schwannomas account for fewer than $1 \%$ of all primary benign bone tumors. ${ }^{16}$ The affected patients 


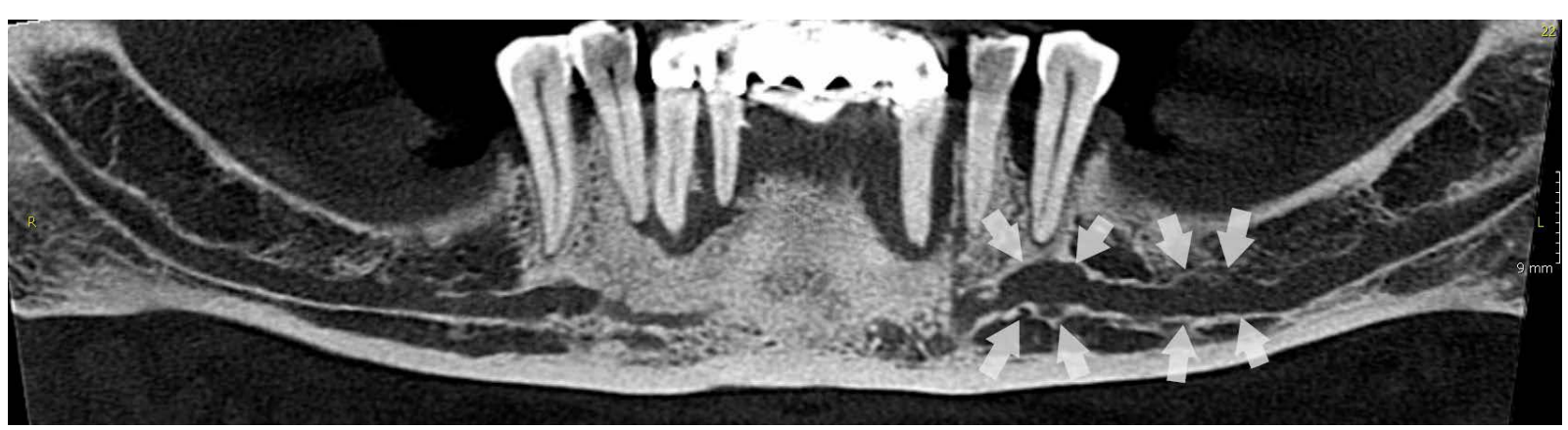

Fig. 3. A panoramic reconstructed cone-beam computed tomographic image shows mandibular canal widening in a patient with schwannoma.

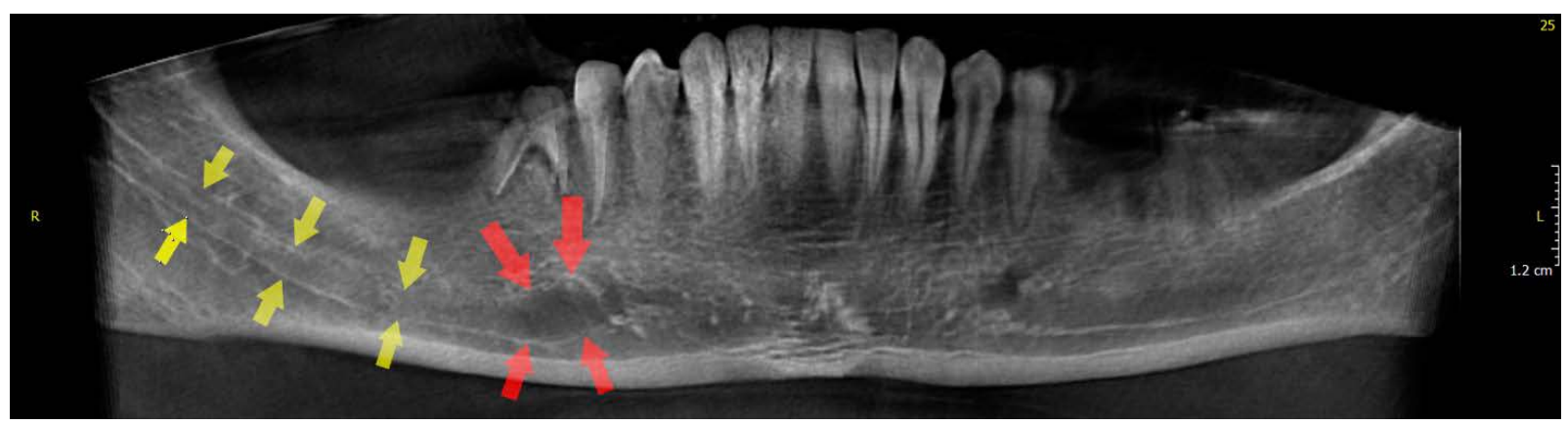

Fig. 4. A panoramic reconstructed cone-beam computed tomographic image shows mandibular canal widening in a patient with neurofibroma (arrows show the normal canal and mandibular canal widening).

were reported to have a mean age of 34 years, and it was found to have a predilection for females. ${ }^{3}$ Schwannomas involve the bone via 3 mechanisms: (1) they may develop centrally in bone, (2) they may arise from the nutrient canals, and (3) a soft tissue lesion may cause erosion or penetrate into the bone. ${ }^{3}$ The mandible is the most commonly affected site, followed by the sacrum. ${ }^{17}$ Clinically, most cases have asymptomatic swelling of the posterior mandible. Pain, tenderness, lip or chin paresthesia, tooth mobility, and tooth displacement are among the less commonly reported findings. ${ }^{18} \mathrm{~A}$ well-circumscribed unilocular radiolucency with a sclerotic margin is characteristic of schwannoma. Root resorption, cortical thinning or erosion, focal radiopacity, multilocularity, cortical expansion, and peripheral scalloping may be present in rare cases. ${ }^{3,18}$ Schwannoma may affect the mandibular canal (Fig. 3) and $10 \%$ of patients may show fusiform widening of the mandibular canal. ${ }^{3}$ Redman et al., ${ }^{19}$ and Chi et al. ${ }^{20}$ reported round or ovoid widening of the mandibular canal in schwannomas of the mandible.

\section{Neurofibroma}

Neurofibroma is the most common peripheral nerve tumor, although it rarely occurs in the oral cavity. It may manifest in 2 clinical forms: peripheral (type I) and central (type II). ${ }^{21,22}$ Controversy exists regarding the frequency of oral manifestations of neurofibroma. A frequency of 4\%-7\% has been reported by some, while values up to $72 \%$ have been reported by others. ${ }^{21}$ In most cases, multiple neurofibromas occur as part of neurofibromatosis. However, solitary masses without visceral manifestations have also been reported. ${ }^{3,22}$ Neurofibromas of the oral cavity most often involve the tongue, followed by the lips, the palate, buccal mucosa, gingiva, floor of the mouth, and pharynx in descending order of frequency. ${ }^{21}$ Intraosseous lesions in the posterior mandible have also been reported to manifest as a well- or poorly-defined unilocular or multilocular radiolucency. ${ }^{22}$ The more frequent occurrence of this entity in the mandible may be due to the long, thick inferior alveolar nerve bundle. ${ }^{23}$ Young adults are more commonly affected than other age groups, and it has a peak incidence in the third decade of life and no sex predilection. ${ }^{22}$ Other radiographic findings include lengthening, narrowing, or rarefaction of the coronoid and articular processes, deepening of the sigmoid notch, and enlargement of the mandibular canal (Fig. 4), mandibular foramen, or mental foramen. ${ }^{21}$ Visnapuu et al. ${ }^{24}$ evaluated 102 neurofibromatosis patients and reported mandibular canal widening in $25 \%$. It 


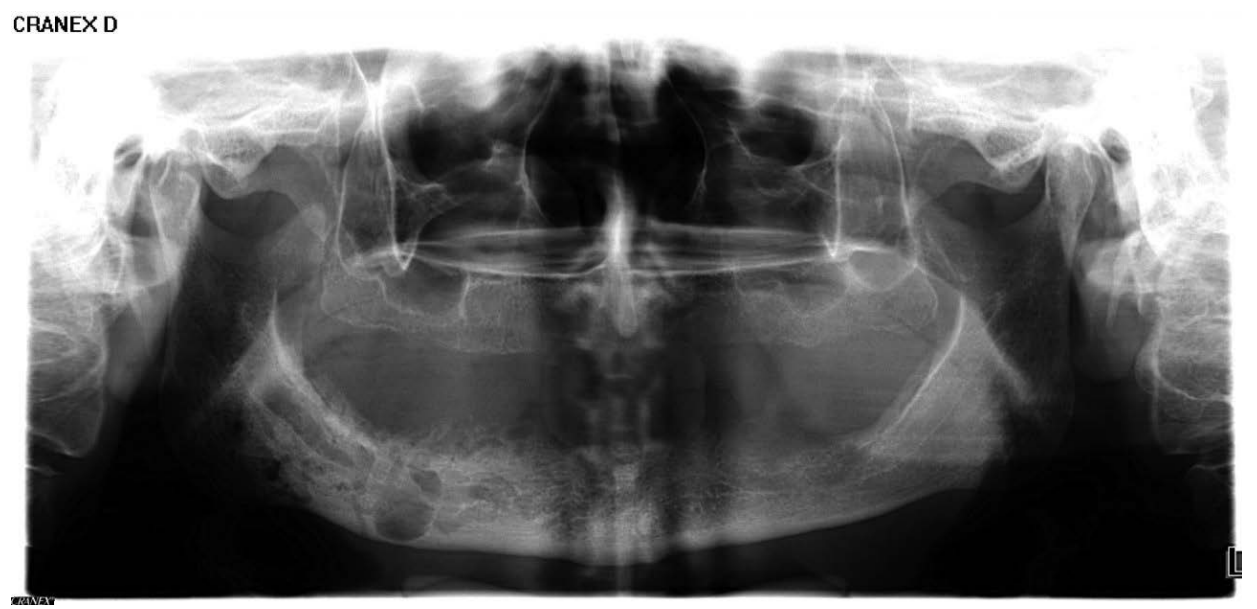

Fig. 5. A panoramic image shows mandibular canal widening in a patient with central hemangioma. was unilateral in over $50 \%$ of the affected patients. Canal enlargement varied from a slight widening to a 2-fold increase in canal diameter. The alveolar canal was undetectable in around $2 \%$ of the patients, and the mandibular canal had an irregular border in the majority of cases. According to Vartiainen et al., ${ }^{18}$ involvement of the alveolar nerve in neurofibromas can lead to development of a fusiform, tubelike, round or ovoid widening of the mandibular canal.

\section{Vascular malformations and hemangiomas}

Vascular lesions are classified into the 2 main categories of vascular malformations and hemangiomas. Vascular malformations are defined as congenital lesions that develop later in life. They are formed by dysplastic vascular channels secondary to hemodynamic mechanisms. ${ }^{25}$ They are rare in the head and neck region; however, $5 \%$ of them are located in the mandible and $50 \%$ are intraosseous lesions. ${ }^{3}$ Swelling, mucosal discoloration at the site, tooth mobility and immediate massive bleeding after extraction of such teeth are common findings. ${ }^{26,27}$ These lesions manifest as unilocular or multilocular cystic lesions with well- or ill-defined borders on radiographs. They may be associated with an enlarged or bifid mandibular canal (Fig. 5). ${ }^{3,18}$ Mandibular canal variations may also be attributed to other vascular lesions, such as hemangiomas, which are benign vasoformative neoplasms of endothelial origin. Some authors believe that hamartomas result from the proliferation of intraosseous mesodermal cells undergoing endothelial differentiation. ${ }^{28}$ Reportedly, $50 \%$ of central hemangiomas are found in the head and neck region, accounting for $1 \%$ of all bony tumors. ${ }^{28,29}$ Hemangiomas are more commonly found in the maxilla, with a female predilection and peak incidence in the second to fifth decades of life. ${ }^{28}$ Vascular lesions of the mandi- ble account for $3.5 \%$ of mandibular tumors. ${ }^{30}$ Mandibular hemangiomas are often congenital; however, some believe that they originate from the mandibular canal, considering the presence of canal widening in most patients. ${ }^{18,28}$ They manifest as multilocular osteolytic lesions with a honeycomb or soap-bubble appearance and irregular, poorly-defined margins in $50 \%$ of patients. $^{29}$

\section{Multiple endocrine neoplasia syndromes}

The multiple endocrine neoplasia (MEN) syndromes are a group of genetic conditions characterized by tumors affecting some certain endocrine glands. ${ }^{31}$ These syndromes are classified as MEN1, MEN-2A, and MEN-2B (or MEN3). The characteristic orofacial manifestations in patients with MEN-2B syndrome are of particular interest to dental professionals. Patients with MEN-2B are at risk of medullary thyroid carcinoma. Once the diagnosis is confirmed, affected individuals are recommended to undergo prophylactic thyroidectomy and neck dissection. ${ }^{31,32}$ The MEN-2B form is more common in women (with a femaleto-male ratio of $1.4: 1$ ), and the mean age of patients has been reported to be 22 years. ${ }^{33}$ The mandibular structures are more commonly affected by this entity. ${ }^{33}$ The orofacial manifestations of patients with MEN-2B include a long lower face, low-set ears, broad-based saddle nose, enlarged nodular lips with submucosal neuromas of the vermilion, circumoral and/or midfacial lentiginosis, severe caries, high arched palate, posterior crossbite, steep mandibular plane, a prognathic or retrognathic mandible, enlarged mental foramen and spacing of the anterior teeth. ${ }^{32}$ Radiographic features include a markedly enlarged, bifurcated mandibular canal and short roots of the lower incisors. ${ }^{33}$ Fusiform and tube-like widening of the mandibular canal has also been reported in patients with MEN2-B. ${ }^{18}$ The same findings 
were reported by Terzic et al. ${ }^{3}$ According to Schenberg, due to the high mortality rate of this condition, patients with the aforementioned characteristics must be further investigated to exclude MEN-2B. ${ }^{34}$

\section{Perineural spreading/invasion}

Perineural spreading is a mode of tumor metastasis distinct from lymphatic and blood vessel invasion. ${ }^{35}$ It refers to tumor dissemination along a nerve, and is seen in $2 \%$ to $55 \%$ of head and neck cancers. Trigeminal and facial nerve involvement has been more commonly reported than involvement of other nerves. ${ }^{36}$ Head and neck malignancies include neoplasms arising from the oral cavity, larynx, pharynx, salivary glands, and nasal airway. ${ }^{35,36}$ Squamous cell carcinoma and adenoid cystic carcinoma are the most common head and neck tumors that exhibit perineural spreading, with reported incidence rates of perineural spreading of $2 \%-30 \%$ and up to $60 \%$, respectively. ${ }^{36}$ Perineural spreading is less common in orofacial malignancies such as lymphoma, melanoma, mucoepidermoid carcinoma, and basal cell carcinoma. ${ }^{35}$ Perineural spreading in squamous cell carcinoma predominantly affects the mandible. It has a male predilection, with a mean age of $56 \pm$ 9 years. ${ }^{37}$ Females are more susceptible to adenoid cystic carcinoma than males, and it is more commonly seen in patients older than 50 years. ${ }^{38}$ Perineural invasion of adenoid cystic carcinoma is more common in the mandible than in other regions. ${ }^{39}$ Persistent paresthesia of the lower lip and chin is a warning sign of a tumor compressing or invading the nerve. The facial and trigeminal nerves form a synapse at 3 locations. These synaptic points could provide a viable route for interneural spread of carcinoma from one nerve to another. ${ }^{40}$ Perineural spreading and invasion can cause inferior alveolar foramen enlargement and mandibular canal widening, and eventually lead to bone destruction. ${ }^{41}$ Diffuse enlargement of the mandibular canal and mental foramen has also been reported in patients with perineural spreading or invasion. ${ }^{3,35,42}$ Fat obliteration in the masticator space and the pterygopalatine fossa or along the mandibular canal should be considered suspicious for tumoral spread, even in the absence of bone destruction. ${ }^{41}$

\section{Miscellaneous conditions}

Localized hypertrophic neuropathy (intraneural perineurioma) is an uncommon cause of mandibular canal widening that leads to fusiform enlargement of the mandibular canal. Vascular leiomyoma causing an ovoid enlargement in the mandibular canal, traumatic neuroma of the inferior alveolar nerve causing a dumbbell-shaped radiolucency in the mandibular canal, inflammatory pseudotumor (plasma cell granuloma, fibrous xanthoma), pseudolymphoma, acromegaly causing diffuse widening or irregularities of the mandibular canal, and Proteus syndrome are among other uncommon causes of mandibular canal widening. ${ }^{3,18}$

\section{Discussion}

Lesions causing mandibular canal widening can be categorized into the following 5 categories: (1) benign or malignant mesenchymal tumors (e.g., non-Hodgkin lymphoma, osteosarcoma, schwannoma, and neurofibroma); (2) hamartomatous lesions (e.g., hemangioma); (3) metabolic diseases and syndromic disorders (e.g., MEN-2B, Proteus syndrome, and acromegaly); (4) lesions with perineural invasion (e.g., squamous cell carcinoma and adenoid cystic carcinoma); and (5) reactive lesions (e.g., inflammatory pseudotumors and pseudolymphoma). Of the aforementioned categories, the 7 entities listed in Table 1 are the most common and should be considered in the list of differential diagnoses in the clinical setting. As shown in Table 1, tube-like or fusiform enlargement of the mandibular canal is by far the most prevalent pattern of canal distension encountered in all categories except for vascular malformations and hemangiomas. ${ }^{3,11,18}$ In contrast, round or ovoid patterns of mandibular canal expansion have been reported in schwannomas and solitary neurofibromas., ${ }^{3,18}$

Although insufficient information is available regarding the incidence of mandibular canal widening, reports have described its occurrence in cases of osteosarcoma (34\%), neurofibroma/neurofibromatosis (25\%), and schwannoma (10\%). ${ }^{3,14,24}$ Thus, mandibular canal widening, along with other radiographic features, should be taken into account to improve the accuracy of the differential diagnosis. For example, enlargement of the mandibular canal and mental foramen accompanied by periodontal ligament widening and the presence of a radiolucency with ragged borders may suggest lymphoma, which would call for additional clinical and/or laboratory investigations to reach a definite diagnosis. $^{3,7,8}$

In the meantime, mandibular canal expansion along with asymmetric periodontal ligament widening, a sun-ray appearance or Codman triangle, or periosteal reaction should prompt the clinician to rule out osteosarcoma through biopsy sampling and other diagnostic aids as soon as possible to obtain an early diagnosis and improve the overall prognosis. $^{12}$

Since the mandibular canal contains nerves and vasculature, its distension might be related to the overgrowth of 
neural and vascular structures, which apply pressure and lead to expansion of the canal wall. ${ }^{30}$ Thus, the expanded shape of the canal may reflect the benign or malignant nature of the lesion. Malignant intracanal neoplasms cause destruction, ragged borders, or disappearance of the canal wall. ${ }^{41}$ Schwannoma and neurofibroma are two neuronal neoplastic lesions that cause canal disfigurement. ${ }^{3,18}$ Other more specific diagnostic modalities should be employed to obtain a more accurate diagnosis; for instance, positive results for the S100 protein indicates a neuronal origin for indwelling lesions. ${ }^{43}$ Vascular malformations and hemangiomas can also cause mandibular canal distension. Advanced imaging techniques, such as magnetic resonance imaging, computed tomography, angiography, and Doppler imaging can help differentiate lesions of vascular origin from other entities. $^{44}$

Dental clinicians may be the first health care providers to suspect a syndrome; for example, mandibular canal expansion accompanied by prominent lips may be suggestive of MEN syndrome. ${ }^{32}$ Early diagnosis of this condition is of utmost importance to reduce the complications associated with neoplasms. In addition, lesions capable of perineural invasion, such as squamous cell carcinoma and adenoid cystic carcinoma, can cause mandibular canal expansion. $^{35,36}$

In conclusion, mandibular canal expansion should be considered as a warning sign necessitating further examination.

\section{References}

1. Ai CJ, Jabar NA, Lan TH, Ramli R. Mandibular canal enlargement: clinical and radiological characteristics. J Clin Imaging Sci 2017; 7: 28.

2. Abdi I, Taheri Talesh K, Yazdani J, Keshavarz Meshkin Fam S, Ghavimi MA, Arta SA. The effect of ameloblastoma and keratocystic odontogenic tumor on the displacement pattern of inferior alveolar canal in CBCT examinations. J Dent Res Dent Clin Dent Prospects 2016; 10: 155-61.

3. Terzic A, Becker M, Imholz B, Scollozi P. Unilateral widening of the inferior alveolar nerve canal: a rare anatomic variant mimicking disease. Oral Radiol 2013; 29: 160-5.

4. Guimarães DM, Pontes FS, Da Mata Rezende Ddos S, Pontes HA. Anatomical variation of mandibular canal simulating a recurrence of odontogenic tumor. Ann Maxillofac Surg 2014; 4: 107-9.

5. Jung YH, Cho BH. Radiographic evaluation of the course and visibility of the mandibular canal. Imaging Sci Dent 2014; 44: 273-8.

6. Munhoz L, Marsan FP, Arita ES. Radiographic enlargement of mandibular canal as an extranodal primary non-Hodgkin's lymphoma early sign in an asymptomatic patient. Case Rep
Dent 2017; 2017: 9193165.

7. Mortazavi H, Baharvand M. Review of common conditions associated with periodontal ligament widening. Imaging Sci Dent 2016; 46: 229-37.

8. Mojaver YN, Sahebjamie M, Tirgary F, Eslami M, Rezvani G. Enlargement of mandibular canal with tongue paresthesia caused by extranodal B-cell lymphoma: a case report. Oral Oncol Extra 2005; 41: 97-9.

9. Buric N, Jovanovic G, Radovanovic Z, Buric M, Tijanic M. Radiographic enlargement of mandibular canal as first feature of non-Hodgkin's lymphoma. Dentomaxillofac Radiol 2010; 39: 383-8.

10. Bertolotto M, Cecchini G, Martinoli C, Perrone R, Garlaschi G. Primary lymphoma of the mandible with diffuse widening of the mandibular canal: report of a case. Eur Radiol 1996; 6: 637-9.

11. Barber HD, Stewart JC, Baxter WD. Non-Hodgkin's lymphoma involving the inferior alveolar canal and mental foramen: report of a case. J Oral Maxillofac Surg 1992; 50: 1334-6.

12. Chittaranjan B, Tejasvi MA, Babu BB, Geetha P. Intramedullary osteosarcoma of the mandible: a clinicoradiologic perspective. J Clin Imaging Sci 2014; 4(Suppl 2): 6.

13. Yagan R, Radivoyevitch M, Bellon EM. Involvement of the mandibular canal: early sign of osteogenic sarcoma of the mandible. Oral Surg Oral Med Oral Pathol 1985; 60: 56-60.

14. Givol N, Buchner A, Taicher S, Kaffe I. Radiological features of osteogenic sarcoma of the jaws. A comparative study of different radiographic modalities. Dentomaxillofac Radiol 1998; 27: 313-20.

15. Garrington GE, Scofield HH, Cornyn J, Hooker SP. Osteosarcoma of the jaws. Analysis of 56 cases. Cancer 1967; 20: 37791.

16. Abouchadi A, Guerrouani A, Ribag Y, El Khatib K, Nassih M. Intrabony schwannoma of the mandible: case report and review of literature. Open J Stomatol 2014; 4: 233-7.

17. Minić AJ. Central schwannoma of the maxilla. Int J Oral Maxillofac Surg 1992; 21: 297-8.

18. Vartiainen VM, Siponen M, Salo T, Rosberg J, Apaja-Sarkkinen M. Widening of the inferior alveolar canal: a case report with atypical lymphocytic infiltration of the nerve. Oral Surg Oral Med Oral Pathol Oral Radiol Endod 2008; 106: e35-9.

19. Redman RS, Guccion JG, Spector CJ, Keegan BP. Cellular schwannoma of the mandible: a case report with ultrastructural and immunohistochemical observations. J Oral Maxillofac Surg 1996; 54: 339-44.

20. Chi AC, Carey J, Muller S. Intraosseous schwannoma of the mandible: a case report and review of the literature. Oral Surg Oral Med Oral Pathol Oral Radiol Endod 2003; 96: 54-65.

21. Khan M, Ohri N. Oral manifestations of Type I neurofibromatosis in a family. J Clin Exp Dent 2011; 3: e483-6.

22. Mortazavi H, Safi Y, Baharvand M, Rahmani S, Jafari S. Peripheral exophytic oral lesions: a clinical decision tree. Int $\mathrm{J}$ Dent 2017; 2017: 9193831.

23. Dalili Z, Adham G. Intraosseous neurofibroma and concurrent involvement of the mandible, maxilla and orbit: report of a case. Iran J Radiol 2012; 9: 45-9.

24. Visnapuu V, Peltonen S, Tammisalo T, Peltonen J, Happonen RP. Radiographic findings in the jaws of patients with neurofi- 
bromatosis 1. J Oral Maxillofac Surg 2012; 70: 1351-7.

25. González-Arriagada WA, Dias MA, Dias PD, MartínezMartínez M, Sena-Filho M, de Almeida OP. Oral encapsulated vascular malformation: an undescribed presentation in the mouth. J Clin Exp Dent 2016; 8: e84-8.

26. Siu WW, Weill A, Gariepy JL, Moret J, Marotta T. Arteriovenous malformation of the mandible: embolization and direct injection therapy. J Vasc Interv Radiol 2001; 12: 1095-8.

27. Sakkas N, Schramm A, Metzger MC, Berlis A, Schmelzeisen $\mathrm{R}$, Otten JE, et al. Arteriovenous malformation of the mandible: a life-threatening situation. Ann Hematol 2007; 86: 40913.

28. Gómez Oliveira G, García-Rozado A, Luaces Rey R. Intraosseous mandibular hemangioma. A case report and review of the literature. Med Oral Patol Oral Cir Bucal 2008; 13: E4968.

29. Ozdemir R, Alagoz S, Uysal AC, Unlu RE, Ortak T, Sensoz O. Intraosseous hemangioma of the mandible: a case report and review of the literature. J Craniofac Surg 2002; 13: 38-43.

30. Vaezeafshar R, Liu SY, Sidell D. Inferior alveolar nerve hemangioma. Laryngoscope 2016; 126: 2168-70.

31. Accurso B, Mercado A, Allen CM. Multiple endocrine neoplasia-2B presenting with orthodontic relapse. Angle Orthod 2010; 80: 585-90.

32. Kahn MA, Cote GJ, Gagel RF. RET protooncogene mutational analysis in multiple endocrine neoplasia syndrome type $2 \mathrm{~B}$ : case report and review of the literature. Oral Surg Oral Med Oral Pathol Oral Radiol Endod 1996; 82: 288-94.

33. Iihara M, Yamashita T, Okamoto T, Kanbe M, Yamazaki K, Egawa $\mathrm{S}$, et al. A nationwide clinical survey of patients with multiple endocrine neoplasia type 2 and familial medullary thyroid carcinoma in Japan. Jpn J Clin Oncol 1997; 27: 12834.

34. Schenberg ME, Zajac JD, Lim-Tio S, Collier NA, Brooks AM, Reade PC. Multiple endocrine neoplasia syndrome - type 2b. Case report and review. Int J Oral Maxillofac Surg 1992;
21: $110-4$.

35. Sundar GT, Sherigar V, Shetty SS, Satya S, Gohil SM. Mandibular canal widening and Bell's palsy: sequelae of perineural invasion in oral cancer. Case Rep Dent 2016; 2016: 3010934.

36. Cox CS, Stallworth DG, Ahmed KA, Wadsworth JT, Wenig B, Chung $\mathrm{CH}$, et al. Perineural tumor spread involving the trigeminal and facial nerves: a review of critical imaging findings. Ann Otolaryngol Rhinol 2017; 4: 1177.

37. Laske RD, Scholz I, Ikenberg K, Meerwein C, Vital DG, Studer G, et al. Perineural invasion in squamous cell carcinoma of the oral cavity: histology, tumor stage, and outcome. Laryngoscope Investig Otolaryngol 2016; 1: 13-8.

38. Dantas AN, Morais EF, Macedo RA, Tinôco JM, Morais Mde L. Clinicopathological characteristics and perineural invasion in adenoid cystic carcinoma: a systematic review. Braz J Otorhinolaryngol 2015; 81: 329-35.

39. Shamim T, Varghese VI, Shameena PM, Sudha S. Primary intraosseous adenoid cystic carcinoma of the mandible with lung metastasis: a case report. J Oral Sci 2008; 50: 95-8.

40. Koivisto T, Chiona D, Milroy LL, McClanahan SB, Ahmad M, Bowles WR. Mandibular canal location: cone-beam computed tomography examination. J Endod 2016; 42: 1018-21.

41. Matzko J, Becker DG, Phillips CD. Obliteration of fat planes by perineural spread of squamous cell carcinoma along the inferior alveolar nerve. AJNR Am J Neuroradiol 1994; 15: 18435.

42. Bagatin M, Orihovac Z, Mohammed AM. Perineural invasion by carcinoma of the lower lip. J Craniomaxillofac Surg 1995; 23: $155-9$.

43. Campos MS, Fontes A, Marocchio LS, Nunes FD, de Sousa SC. Clinicopathologic and immunohistochemical features of oral neurofibroma. Acta Odontol Scand 2012; 70: 577-82.

44. Naikmasur VG, Sattur AP, Burde K, Nandimath K, Thakur AR. Central hemangioma of the mandible: role of imaging in evaluation. Oral Radiol 2010; 26: 46-51. 